\title{
www.czasopisma.pan.pl \\ Resistance of WE43 and ZRE1 Magnesium Alloys to Gas Corrosion
}

\author{
R. Przeliorz *, J. Piątkowski \\ Faculty of Materials Engineering and Metallurgy, Silesian University of Technology, \\ Krasińskiego 8, 40-019 Katowice, Poland \\ * Corresponding author. E-mail address: roman.przeliorz@polsl.pl
}

Received 14.09.2016; accepted in revised form 20.12.2016

\begin{abstract}
In spite of the fact that in most applications, magnesium alloys are intended for operation in environments with room temperature, these alloys are subject to elevated temperature and oxidizing atmosphere in various stages of preparation (casting, welding, thermal treatment). At present, the studies focus on development of alloys with magnesium matrix, intended for plastic forming. The paper presents results of studies on oxidation rate of WE43 and ZRE1 magnesium foundry alloys in dry and humidified atmosphere of $\mathrm{N}_{2}+1 \% \mathrm{O}_{2}$. Measurements of the oxidation rate were carried out using a Setaram thermobalance in the temperature range of $350-480^{\circ} \mathrm{C}$. Corrosion products were analyzed by SEM-SEI, BSE and EDS. It was found that the oxide layer on the WE43 alloy has a very good resistance to oxidation. The high protective properties of the layer should be attributed to the presence of yttrium in this alloy. On the other hand, a porous, two-layer scale with a low adhesion to the substrate forms on the ZRE1 alloy. The increase in the sample mass in dry gas is lower than that in humidified gas.
\end{abstract}

Keywords: Wear resistant alloys, Magnesium alloys, Oxidation resistance

\section{Introduction}

Such advantages of magnesium as: low specific gravity, good castability, susceptibility to mechanical working and ease of recycling have led to an increase in the use of magnesium by 10 to $15 \%$ per year $[1,2]$. Elevated temperature leads to a change in its chemical composition and a decrease in performance of the top layer. A layer damaged by overheating must be removed before casting or plastic forming. It results in material losses and moreover causes a decrease in technological properties of semifinished products. These alloys are characterized by a high strength, a good resistance to gas corrosion and excellent plastic properties at elevated temperatures. Their group includes alloys from $\mathrm{Mg}-\mathrm{Zn}$ and $\mathrm{Mg}-\mathrm{Gd}$ equilibrium systems with additions of rare-earth metals $\mathrm{Y}$ and $\mathrm{Zr}$. After thermal treatment operations of supersaturation and aging, these alloys have good strength properties at room temperature and a better creep resistance at elevated temperature, while compared to conventional alloys, e.g. WE43 having the best mechanical properties among Mg alloys known hitherto $[3,4]$. In spite of the fact that magnesium alloys are intended for operation at room temperature, those applicable at temperatures of $200-300^{\circ} \mathrm{C}$ are more promising [5]. Knowledge on kinetics of oxidation of magnesium-based alloys at an elevated temperature is important because of their use as light structural materials in aeronautics and automotive industry. It was found that a layer of $\mathrm{MgO}$ has a good resistance to oxidation only at low temperature [6]. During oxidation at an elevated temperature, a porous $\mathrm{MgO}$ layer forms on the surface of alloys, in the result of density difference between $\mathrm{Mg}$ and $\mathrm{MgO}$ [7]. Fourneir et al. [8] studied behavior of magnesium during oxidation in oxygen in the temperature range from room temperature to $400^{\circ} \mathrm{C}$. Their results indicate that oxide growth in dry oxygen at $300^{\circ} \mathrm{C}$ is inversely logarithmic. The oxide layer is thin and has a very good resistance 
to oxidation. In paper [9], the oxidation kinetics and the structure of the oxide layer formed on $\mathrm{Mg}$ and $\mathrm{Mg}$-Ca were studied. The measurements were carried out in air at $300^{\circ} \mathrm{C}$ and $450^{\circ} \mathrm{C}$. It was shown that at $450^{\circ} \mathrm{C}$, an addition of $\mathrm{Ca}$ to $\mathrm{Mg}$ delays the oxidation process, but accelerates it at $300^{\circ} \mathrm{C}$. The influence of the microstructure on the oxidation mechanism and kinetics was analyzed in paper [10]. It was found, among other, that corrosion resistance of a supercooled $\mathrm{MgNiY}$ alloy $(87 \% \mathrm{Mg}, 12 \% \mathrm{Ni}, 1 \%$ $\mathrm{Y})$ with an amorphous structure does not differ significantly from a nanocrystalline structure (average grain size of $100 \mathrm{~nm}$ ), but it is much higher that that of a typical crystalline structure.

\section{Aim and scope of the studies}

The aim of the paper is to study the oxidation kinetics in order to compare the corrosion resistance of WE43 and ZRE1 magnesium foundry alloys in dry and humidified $\mathrm{N}_{2}+1 \% \mathrm{O}_{2}$ gas. Concentration of water vapor in the gas was $1 \%$ by vol. The scope of the study includes, among others:

- studies on oxidation by thermogravimetry,

- analysis of change of mass vs. time for the studied alloys,

- metallographic studies,

- summary and conclusions.

\section{Material and methodology}

The studies were carried out using WE43 and ZRE1 magnesium foundry alloys. The alloys differed in zinc, yttrium and neodymium contents. The measurements of the oxidation rate were carried out by continuous thermogravimetry using a Setaram thermobalance. Samples with a shape of a rectangular prism were oxidized in the temperature range of $350-480^{\circ} \mathrm{C}$. Dry and humidified $\mathrm{N}_{2}+1 \% \mathrm{O}_{2}$ constituted the oxidizing atmosphere. The gas was humidified with water at $10^{\circ} \mathrm{C}\left(\mathrm{p}_{\text {(water) }}=0.012 \mathrm{~atm}\right)$. The gas flow rate was $1.21 \cdot h^{-1}$. After oxidation, the sample surfaces were analyzed using a HITACHI S-3400N electron microscope.

\section{Results and their analysis}

Chemical composition of WE43 and ZRE1 alloys is shown in Table 1.

Table 1.

Chemical composition of WE43 and ZRE1 magnesium alloys, wt. \%

\begin{tabular}{cccccccc}
\hline Alloy & $\mathrm{Zn}$ & $\mathrm{Al}$ & $\mathrm{Si}$ & $\mathrm{Cu}$ & $\mathrm{Mn}$ & $\mathrm{Fe}$ & $\mathrm{Ni}$ \\
\hline \multirow{3}{*}{ WE43 } & 0.01 & - & 0.01 & $<0.04$ & $<0.01$ & 0.02 & $<0.04$ \\
\cline { 2 - 9 } & $\mathrm{Ag}$ & $\mathrm{Li}$ & $\mathrm{Zr}$ & $\mathrm{Y}$ & $\mathrm{Nd}$ & $\mathrm{RE}$ & $\mathrm{Mg}$ \\
\cline { 2 - 8 } & - & $<0.01$ & 0.51 & 3.70 & 2.20 & 0.96 & matrix \\
\hline \multirow{4}{*}{ ZRE1 } & $\mathrm{Zn}$ & $\mathrm{Al}$ & $\mathrm{Si}$ & $\mathrm{Cu}$ & $\mathrm{Mn}$ & $\mathrm{Fe}$ & $\mathrm{Ni}$ \\
\cline { 2 - 9 } & 2.80 & 0.01 & $<0.01$ & $<0.01$ & $<0.03$ & 0.03 & $<0.01$ \\
\cline { 2 - 8 } & $\mathrm{Ag}$ & $\mathrm{Li}$ & $\mathrm{Zr}$ & $\mathrm{Y}$ & $\mathrm{Nd}$ & $\mathrm{RE}$ & $\mathrm{Mg}$ \\
\cline { 2 - 8 } & - & - & 0.51 & - & - & 2.87 & matrix \\
\hline
\end{tabular}

Mass increase curves for WE43 and ZRE1 alloys are shown in Figure 1.

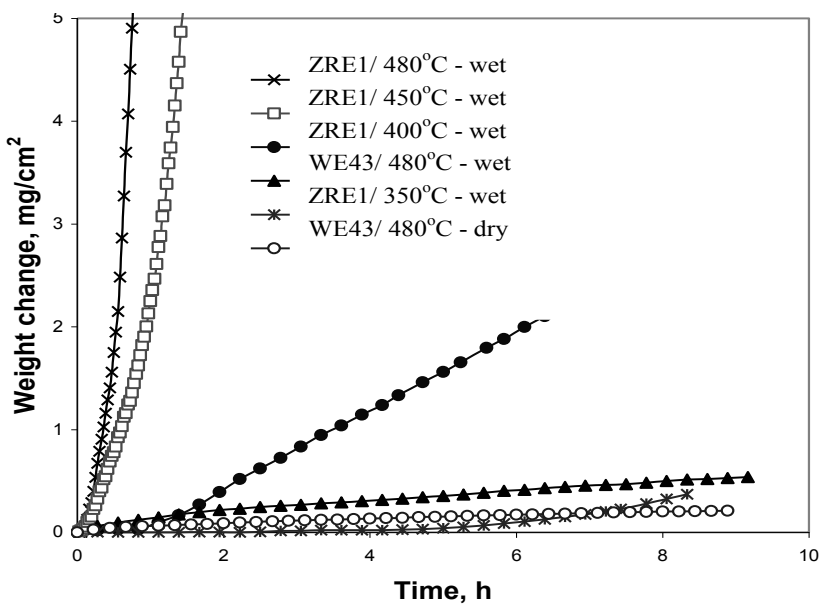

Fig. 1. Change in mass vs. time for WE43 and ZRE1 alloys oxidized in atmosphere of $\mathrm{N}_{2}+1 \%$ by vol. $\mathrm{O}_{2}$, dry and humidified

Analysis of the curves indicates that the dependence of the mass increase on the oxidation time is parabolic for the WE43 alloy in dry and humidified gas (Equation 1). Parabolic course of the oxidation means that diffusion of reagents in the reaction product phase (diffusion of metal cations or oxygen anions) is the slowest elementary process determining the scale growth.

The mass increase in dry gas is lower than that in humidified gas.

$\left(\frac{\Delta \mathrm{m}}{\mathrm{s}}\right)^{2}=\mathrm{k}_{\mathrm{p}}^{\prime \prime} \cdot \tau+\mathrm{C}$

where:

$\Delta \mathrm{m}$ - mass increase per unit area s in time $\tau$,

$k_{p}^{\prime \prime}$ - parabolic rate constant, $\mathrm{g}^{2} \cdot \mathrm{cm}^{-4} \cdot \mathrm{s}^{-1}$,

C - constant connected with deviation from the parabolic dependence in the initial reaction period.

Oxidation of the ZRE1 alloy changes from a linear dependence to violent reaction, with an increasing rate. The accelerated reaction is preceded by an undefined period (incubation). Duration of the incubation period characterized by a slight mass increase depends on temperature.

At $350^{\circ} \mathrm{C}$, the duration was approx. 5 hours, while at $400^{\circ} \mathrm{C}-$ approx. $50 \mathrm{~min}$. Above the temperature of $400^{\circ} \mathrm{C}$, oxidation occurs with a rate increasing in time from the beginning of the reaction.

Morphology and chemical composition of the outer surface of the oxide layer formed on the WE43 and ZRE1 alloys is shown in Figures 2-4. The oxide layer formed on the WE43 alloy in dry gas contains mainly magnesium and yttrium. Presence of neodymium and gadolinium has been found. In humidified gas, chlorine, calcium, sodium, potassium and silicon occur additionally apart from the aforementioned elements. The outer surface of the scale formed on the ZRE1 alloy contains magnesium and zinc, and small amounts of chlorine, potassium and aluminum (Figure 4). 


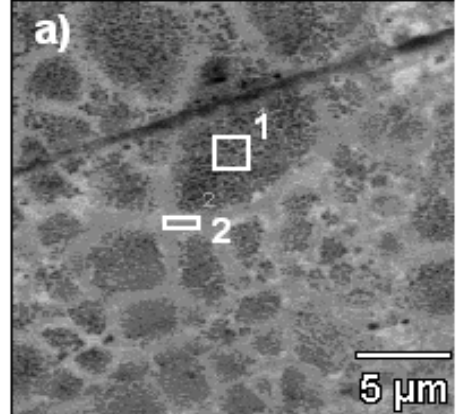

Full scale counts

pt1

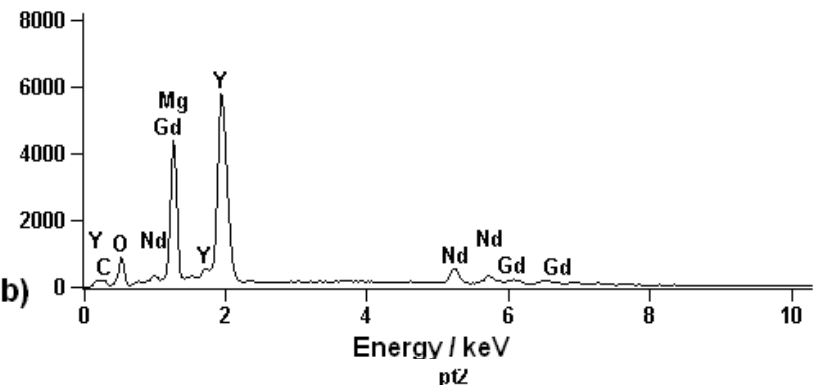

Full scale counts

pt2

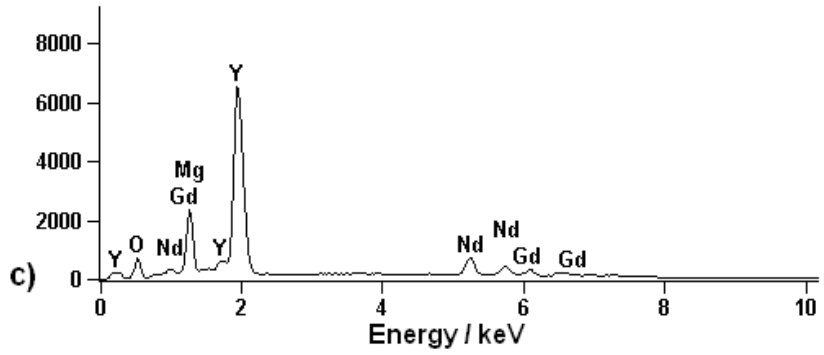

Fig. 2. Morphology and EDS analysis from the surface of the oxide layer formed on the WE43 alloy in dry gas together with its chemical composition: a) the outer surface of the oxide layer, $\mathrm{b}$ and c) chemical composition of the layer, $\mathrm{t}=480^{\circ} \mathrm{C}$

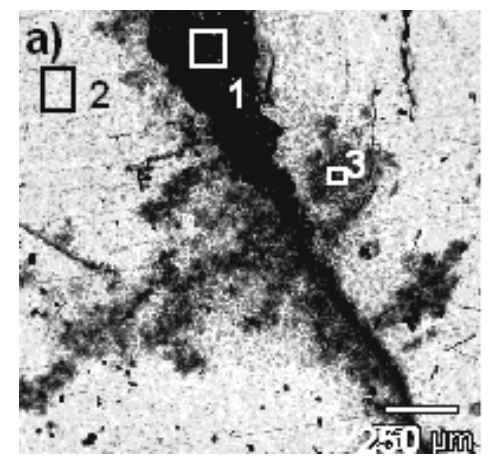

Fig. 3. Microstructure of the surface of the oxide layer on the WE43 alloy after oxidation in humidified gas, $\mathrm{t}=480^{\circ} \mathrm{C}$
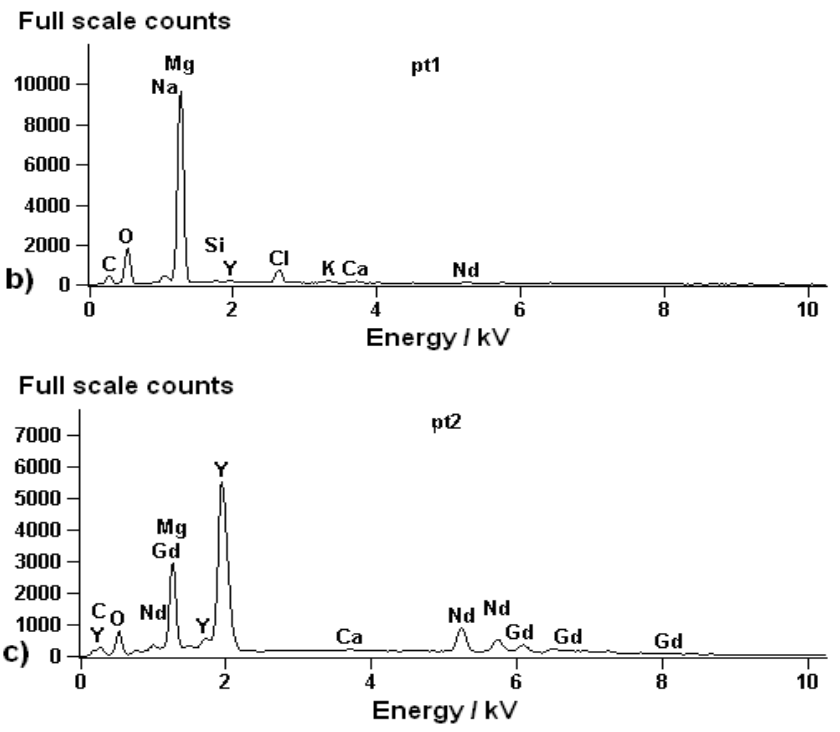

Full scale counts

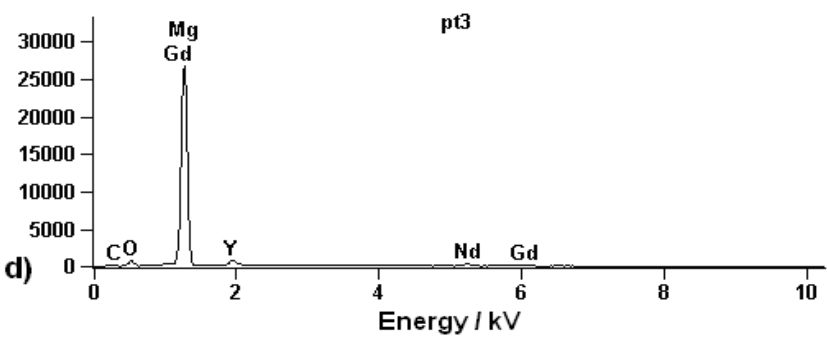

Fig. 4. EDS analysis from Fig. 3. of the surface of the oxide layer on the WE43 alloy after oxidation in humidified gas, $\mathrm{t}=480^{\circ} \mathrm{C}$, and its chemical compositions in points $1 ; 2 ; 3$

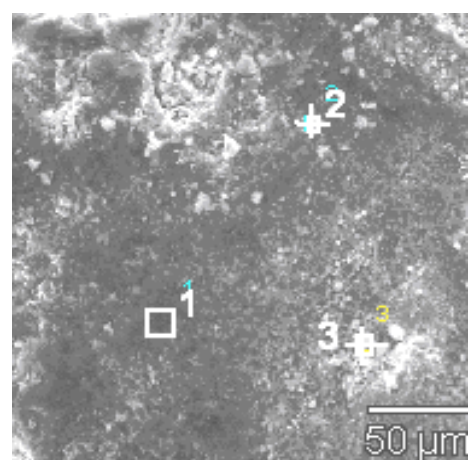

Fig. 5. Microstructure of the surface of the oxide layer on the ZRE1 alloy after oxidation in humidified gas, $\mathrm{t}=480^{\circ} \mathrm{C}$ 


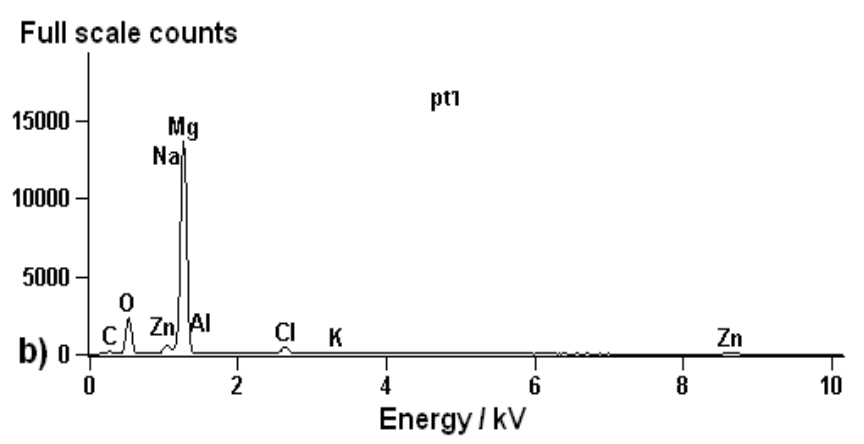

Full scale counts

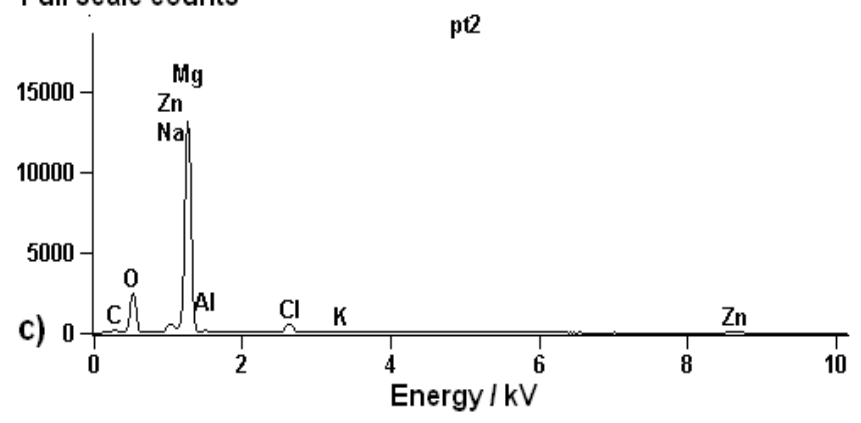

Full scale counts

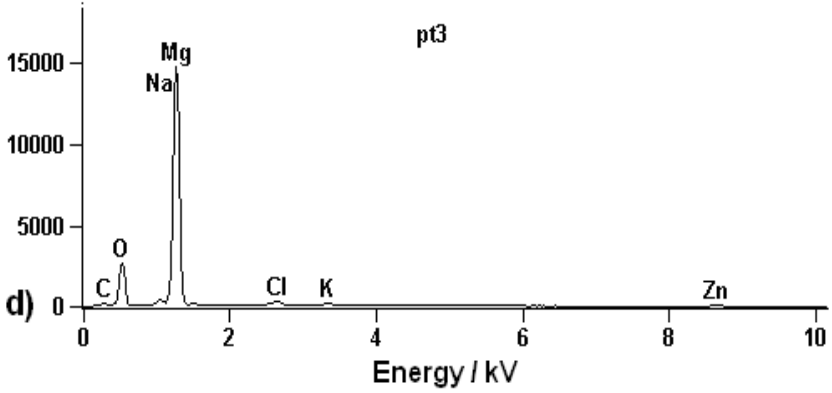

Fig. 6. EDS analysis from Fig. 5 of the surface of the scale on the ZRE1 alloy after oxidation in humidified gas, $\mathrm{t}=480^{\circ} \mathrm{C}$, and its chemical compositions in points $1 ; 2 ; 3$

Thickness of the oxide layer on the WE43 alloy in dry gas amounts to approx. $1.3 \mu \mathrm{m}$, while in humidified gas - approx. 1.7 $\mu \mathrm{m}$. The oxide layer is compact and it adheres well to the substrate (Figure 7).
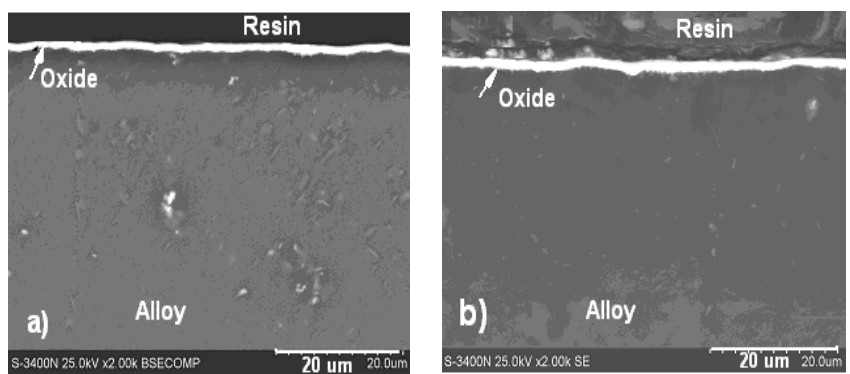

Fig. 7. Cross section of the oxide layer formed on the WE43 alloy, a) dry gas, b) humidified gas, $\mathrm{t}=480^{\circ} \mathrm{C}$
The scale on the ZRE1 alloy is two-layered. Pores form at the boundary between the external and internal layers. Thickness of the scale in dry gas amounts to approx. $195 \mu \mathrm{m}$ (Figure 8). In humidified gas, the outer layer of the scale had white color and was flaking easily. It does not constitute a barrier protecting from oxidation at a temperature above $350^{\circ} \mathrm{C}$.

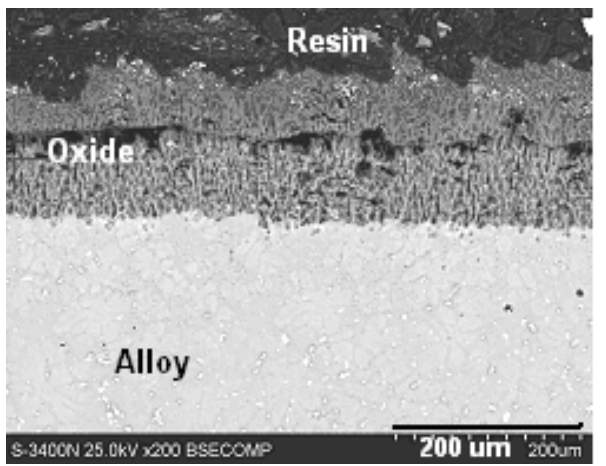

Fig. 8. Cross section of the oxide layer formed on the ZRE1 alloy in dry gas, $\mathrm{t}=400^{\circ} \mathrm{C}$

Calculations of free enthalpy carried out using the methodology published in paper [11] indicate that the following reactions on magnesium alloys are possible:

$$
\begin{aligned}
& 2 \mathrm{Mg}+\mathrm{O}_{2(\mathrm{~g})}=2 \mathrm{MgO}, \quad \Delta \mathrm{G}_{480^{\circ} \mathrm{C}}=-1039,8 \mathrm{~kJ} / \mathrm{molO}_{2} \\
& \frac{4}{3} \mathrm{Y}+\mathrm{O}_{2(\mathrm{~g})}=\frac{2}{3} \mathrm{Y}_{2} \mathrm{O}_{3}, \quad \Delta \mathrm{G}_{480^{\circ} \mathrm{C}}=-1122,6 \mathrm{~kJ} / \mathrm{molO}_{2} \\
& \frac{4}{3} \mathrm{Nd}+\mathrm{O}_{2(\mathrm{~g})}=\frac{2}{3} \mathrm{Nd}_{2} \mathrm{O}_{3}, \quad \Delta \mathrm{G}_{480^{\circ} \mathrm{C}}=-1061,9 \mathrm{~kJ} / \mathrm{molO}_{2}
\end{aligned}
$$

Also, a reaction of transformation of magnesium oxide into yttrium or neodymium oxide is possible:

$\frac{3}{2} \mathrm{MgO}+\mathrm{Y}=\frac{3}{2} \mathrm{Mg}+\frac{1}{2} \mathrm{Y}_{2} \mathrm{O}_{3}, \quad \Delta \mathrm{G}_{480^{\circ} \mathrm{C}}=-62,0 \mathrm{~kJ} / \mathrm{molY}$

$\frac{3}{2} \mathrm{MgO}+\mathrm{Nd}=\frac{3}{2} \mathrm{Mg}+\frac{1}{2} \mathrm{Nd}_{2} \mathrm{O}_{3}, \quad \Delta \mathrm{G}_{480^{\circ} \mathrm{C}}=-16,3 \mathrm{~kJ} / \mathrm{molNd}$

According to thermodynamics, oxides with a high dissociation pressure will form at the oxidizer-scale phase boundary, while those with a low dissociation pressure - in the internal part of the scale. Thus, the oxide layer on the WE43 alloy should consist of $\mathrm{MgO}$ in its external part, and $\mathrm{Y}_{2} \mathrm{O}_{3}$ and $\mathrm{Nd}_{2} \mathrm{O}_{3}$ (or a mixed oxide $(\mathrm{YNd})_{2} \mathrm{O}_{3}$ ) near the alloy-oxide phase boundary. A comparison of values of the free enthalpy change indicates (reactions 2-4) that initially magnesium, yttrium and neodymium may be oxidized simultaneously. However, gradually, $\mathrm{MgO}$ should prevail in the scale in the result of a greater diffusion of $\mathrm{Mg}^{2+}$ ions than that of $\mathrm{Y}^{3+}$ ions. Diffusion coefficient of $\mathrm{Mg}^{2+}$ ions in the $\mathrm{MgO}$ lattice amounts to $\mathrm{D}_{\mathrm{Mg}}=1 \cdot 10^{-6} \exp (-150000 / \mathrm{RT})$ [12], while that of $\mathrm{Y}^{3+}$ in $\mathrm{Y}_{2} \mathrm{O}_{3}-\mathrm{D}_{\mathrm{Y}}=1 \cdot 10^{-9} \exp (-300000 / \mathrm{RT}), \mathrm{m}^{2} \cdot \mathrm{s}^{-1}[13]$. 
Formation of a protective layer of $\mathrm{Y}_{2} \mathrm{O}_{3}$ and $\mathrm{Nd}_{2} \mathrm{O}_{3}$ is possible if concentration of yttrium or neodymium in the alloy is higher than the equilibrium concentration. Based on dependencies (7) and (8), one can calculate critical activity of yttrium and neodymium in the alloy, at which $\mathrm{MgO}$ may coexist with the metallic phase:

$$
\begin{gathered}
\Delta \mathrm{G}_{480^{\circ} \mathrm{C}}=-R T \ln \frac{\mathrm{a}_{\mathrm{Mg}}^{3 / 2}}{\mathrm{a}_{\mathrm{Y}}} \\
\Delta \mathrm{G}_{480^{\circ} \mathrm{C}}=-\mathrm{RT} \ln \frac{\mathrm{a}_{\mathrm{Mg}}^{3 / 2}}{\mathrm{a}_{\mathrm{Nd}}}
\end{gathered}
$$

for the sake of simplicity, activity of $\mathrm{Mg}$ is replaced with molar fraction.

So-calculated activity of yttrium in the state of equilibrium with $\mathrm{MgO}$ amounts to approx. $5 \cdot 10^{-5}$, and that of neodymium approx. $10^{-1}$. It results from the above that yttrium will be oxidized at the scale-alloy phase boundary under the layer of magnesium oxide, even at a low content of yttrium in the alloy, while neodymium - at a significantly higher content. In paper [14], it was found that an addition of neodymium changes the oxidation kinetics from a linear dependence to a parabolic one, increasing the resistance to oxidation. Zinc in magnesium alloys affect the aging process [5]. At elevated temperature, zinc oxide forms. Zinc increases the oxidation rate in the result of formation of pores in the scale Generation of pores and voids may be also a result of formation of gaseous $\mathrm{Mg}(\mathrm{OH})_{2}$ [15]. The flaws mentioned above lead to a linear or accelerated course of oxidation of the ZRE1 alloy.

\section{Conclusions}

Based on the research carried out, the following conclusions were formulated:

1. In the temperature range of $350-480^{\circ} \mathrm{C}$, the dependence between the mass increase and the time of oxidation of the WE43 alloy is parabolic. The alloy exhibits a good resistance to oxidation.

2. The scale formed on the ZRE1 alloy does not exhibit protective properties. The oxide layer is multi-layered, it flakes and drops of easily from the substrate.

3. The increase in the sample mass is higher in the presence of water vapor than in dry gas.

\section{Acknowledgements}

This work was supported by Polish Ministry for Science and Higher Education under internal grant BK264/RM2/2016 for Institute of Metals Technology, Silesian University of Technology, Poland.

\section{References}

[1] Medved, J., Primoz, C., Mrvar C. \& Voncina M. (2009). Oxidation Resistance of Cast Magnesium Alloys. Oxidation Materials. 71, 257-270.

[2] Czerwiński, F. (2004). Factors Affecting the Oxidation Nature of Magnesium Alloys. JOM. 29-31.

[3] Zhang, Y., Zeng, X., Liu, L., Lu, Ch., Zhou, H., Li, Q. \& Zhu Y. (2004). Effects of Yttrium on Microstructure and Mechanical Properties of Hot-extruded $\mathrm{Mg}_{92,3} \mathrm{Zn}_{5,8} \mathrm{Y}_{1,2} \mathrm{Zr}_{0,7}$ Alloys. Materials Science and Engineering. A 373, 320-327.

[4] Liu, X.B., Chen, R. S. \& Han, E. H. (2008). Effects of Ageing Treatment on Microstructures and Properties of $\mathrm{Mg}_{86,3} \mathrm{Gd}_{10} \mathrm{Y}_{3} \mathrm{Zr}_{0,7}$ Alloys with and Without $\mathrm{Zn}$ Additions. Journal of Alloys and Compounds. 465, 232-238.

[5] Liu, J., Li, Y. \& Wang, Y. F. (2009). The High Temperature Oxidation Behavior of $\mathrm{Mg}_{88,5} \mathrm{Gd}_{10} \mathrm{Y}_{2} \mathrm{Zr}_{0,5}$ Alloy, Oxidation Materials. 71, 319-334.

[6] Spassov, T., Alves, H. \& Köster U. (2002). Oxidation of Rapidly Solidified $\mathrm{Mg}_{87} \mathrm{Ni}_{12} \mathrm{Y}_{1}$ Alloy. Journal of Alloys and Compounds. 336, 163-169.

[7] Zeng, X. Q., Wang, Q. D., Lu, Y. Z., Ding, W. J., Lu, C., Zu, Y. P,. Zhai, C. Q. \& Xu, X. P. (2000). Kinetic study on the surface oxidation of the molten $\mathrm{Mg}_{90,2} 9 \mathrm{Al}_{9} \mathrm{Zn}_{0,5} \mathrm{Be}_{0,3}$, alloy. Journal of Materials Science. 36 , 2499-2504

[8] Fourneir, V., Marcus P. \& Olefjord, I. (2002). Oxidation of magnesium. Surf. Interface Anal. 34, 494.

[9] Seong-Ho, Ha., Jin-Kyu, Lee, \& Shae, K. Kim. (2008). Effect of $\mathrm{CaO}$ on Oxidation Resistance and Microstructure of Pure Mg. Materials Transactions. 49(5), 1081-1083.

[10] Przeliorz, R. \& Piątkowski J. (2015). Corrosion of the WE43 and MSR-B Magnesium Alloys in $\mathrm{CO}_{2}$. Metalurgija. 55(3), 429-432.

[11] Czerwiński, F. (2003). The Oxidation of Mg Alloys In Solid And Semisolid States. Metals \& Materials Society. 30-42.

[12] Gaboriaud, R.J. (1980). Self-diffusion of Yttrium in Monocrystaline Yttrium Oxide $\mathrm{Y}_{2} \mathrm{O}_{3}$. Journal of Solid Chemistry. 35, 252-261.

[13] Wang, X.M., Zeng, X.Q., Wu, G.S., Yao, S.S. \& Li, L.B. (2007). Surface Oxidation Behavior of MgNd Alloys. Applied Surface Science. 253, 9017-9023.

[14] Czerwinski, F. (2002). The Oxidation Behavior of an AZ91D Magnesium Alloy at High Temperatures. Acta Materialia. 50, 2639-2654.

[15] Wang, X.M., Zeng, X.Q., Zhou, Y., Wu, G.S., Yao, S.S. \& Lai Y.J. (2008). Early Oxidation Behaviors of Mg-Y Alloys at High Temperatures. Journal of Alloys and Compounds. 460, 368-374. 